\title{
Direct correlation of charge transfer absorption with molecular donor:acceptor interfacial area via photothermal deflection spectroscopy
}

\author{
Ester Buchaca-Domingo, Koen Vandewal, Zhuping Fei, Scott E. Watkins, \\ Fiona H. Scholes, James H Bannock, John de Mello, Lee J. Richter, Dean M. \\ DeLongchamp, Aram Amassian, Martin Heeney, Alberto Salleo, and Natalie Stingelin
}

J. Am. Chem. Soc., Just Accepted Manuscript • DOI: 10.1021/ja512410f • Publication Date (Web): 09 Apr 2015

Downloaded from http://pubs.acs.org on April 14, 2015

\section{Just Accepted}

"Just Accepted" manuscripts have been peer-reviewed and accepted for publication. They are posted online prior to technical editing, formatting for publication and author proofing. The American Chemical Society provides "Just Accepted" as a free service to the research community to expedite the dissemination of scientific material as soon as possible after acceptance. "Just Accepted" manuscripts appear in full in PDF format accompanied by an HTML abstract. "Just Accepted" manuscripts have been fully peer reviewed, but should not be considered the official version of record. They are accessible to all readers and citable by the Digital Object Identifier (DOI®). "Just Accepted" is an optional service offered to authors. Therefore, the "Just Accepted" Web site may not include all articles that will be published in the journal. After a manuscript is technically edited and formatted, it will be removed from the "Just Accepted" Web site and published as an ASAP article. Note that technical editing may introduce minor changes to the manuscript text and/or graphics which could affect content, and all legal disclaimers and ethical guidelines that apply to the journal pertain. ACS cannot be held responsible for errors or consequences arising from the use of information contained in these "Just Accepted" manuscripts.

\section{ACS Publications}


In BHJ solar cells, charge carriers are generated, but also recombine via interfacial CT states. Since such CT states likely originate from areas where the donor and acceptor are in close proximity, there should be an optimal density of donor:acceptor interfaces that can maximize the former processes (i.e. exciton harvesting and free carrier generation) while minimizing the electron-hole recombination. ${ }^{1}$ However, a clear, structural picture of how to realize this is still missing, partly because it has been challenging $(a)$ to quantify the properties of individual

\begin{abstract}
Here, we show that the Charge Transfer (CT) absorption signal in bulk-heterojunction (BHJ) solar cell blends, measured by photothermal deflection spectroscopy (PDS), is directly proportional to the density of molecular donor/acceptor interfaces. Since the optical transitions from ground state to the interfacial CT state are weakly allowed at photon energies below the optical gap of both donor and acceptor, we can exploit the use of this sensitive linear absorption spectroscopy for such quantification. Moreover, we determine the absolute molar extinction coefficient of the CT transition for an archetypical polymer-fullerene interface. The latter is $\sim 100$ times lower than the extinction coefficient of the donor chromophore involved, allowing us to experimentally estimate the transition dipole moment (0.3D) and the electronic coupling between ground state and CT state to be on the order of $30 \mathrm{meV}$.
\end{abstract}

interfacial CT states, such as their energetics and electronic coupling to the ground state and $(b)$ to identify the amount of functional donoracceptor contacts that are present in a given architecture and may lead to such interfacial CT states.

The establishment of relevant structure/property interrelationships with respect to interfacial $\mathrm{CT}$ states will likely require that intermixed phases between the donor and acceptor are taken into account. These intermixed phases commonly result from the often considerable miscibility of fullerene derivatives within the fractions of the donor polymer that are of low molecular order - which is a rather universal behavior for binary polymer:fullerene blends. ${ }^{2,3}$ Here, we employ poly(2,5-bis(3-alkylthiophene-2-yl)thieno [3,2-b] thiophene)s (pBTTT) ${ }^{4}$ as the donor material and [6,6]-phenyl $\mathrm{C}_{61}$-butyric acid methyl ester $\left(\mathrm{PC}_{61} \mathrm{BM}\right)$ as the acceptor (see Fig.la for the chemical structures) and use suitable additives to direct the intermixing of the two components and, thus, the amount of molecular interfaces without changing the donor:acceptor composition ratio. ${ }^{3 \mathrm{e}}$ This enables us to establish a correlation between the phase morphology and the sub-gap absorption strength that originates from direct $\mathrm{CT}$ absorption. In order to demonstrate the ability of PDS to determine the relative interfacial contact area in polymer:fullerene mixed phases, we further apply this method to quantify the effect of the same additives in poly(3hexylthiophene) $(\mathrm{P} 3 \mathrm{HT})^{5}$ and $\mathrm{PC}_{61} \mathrm{BM}$ blends on their optoelectronic properties by assessing the varying amount of the intermixed amorphous phase in the different systems using photolumiscence (PL), UV-vis and PDS spectroscopy. 
pBTTT was selected as the initial donor polymer because it is a conjugated polymer that is able to host certain fullerene derivatives such as $\mathrm{PC}_{61} \mathrm{BM}$ in "cavities" within their molecular arrangements to form a co-crystal phase, ${ }^{6}$ providing a well-defined model for donor polymer:fullerene intermixed regions. Indeed, the co-crystal represents an ordered intermixed phase that can be readily probed by structural techniques such as X-ray diffraction, ${ }^{2 c, 7}$ in contrast to the intermixed amorphous solid solutions formed by, for instance, the molecularly disordered fractions in $\mathrm{P} 3 \mathrm{HT}$ in which fullerenes such as $\mathrm{PC}_{61} \mathrm{BM}$ are miscible. Addition of methyl esters of certain fatty acids allows the manipulation of co-crystal formation, ${ }^{3 \mathrm{e}}$ leading to predominantly 2-phase systems composed of relatively phase-pure polymer and fullerene domains when myristic acid methyl ester (Me14) or dodecanoic acid methyl ester (Me12) are used as additives; morphologies containing three phases (phase-pure polymer and fullerene regions, as well as an intermixed domains comprised of the cocrystal phase) are obtained when heptanoic acid methyl ester (Me7) is employed. More recently, a structural picture of the resulting ternary systems ( $\mathrm{pBTTT}$ : additive: $\mathrm{PC}_{61} \mathrm{BM}$ ) has further been substantiated with photo-physical evidence that fit our view of what phase morphologies can be achieved in pBTTT:PC ${ }_{61}$ BM blends when specific fatty acid esters are added. ${ }^{8}$ These additives, i.e. Me7, Me12 and Me14, were, however, not intended to act as plasticicers such as processing additives like 1,8-diiodooctane (DIO), 1,8-octanedithiol (ODT) and 1,8dichlorooctane (DCO) which are frequently applied to modify the morphology of the active layer to realize an improvement of device performance. ${ }^{9}$ Note that while trace solvent is commonly found in coat films, no significant traces of additive were detected after two hours of film formation (further details are given in Ref. 3e and Fig. S1 in SI). While we cannot exclude that a minute fraction stays in the film, all evidence collected so far (including data presented in this work) suggests that even if trace amounts of additives were present, these would not negatively affect the behavior of the $\mathrm{pBTTT}: \mathrm{PC}_{61} \mathrm{BM}$ blend. ${ }^{3 \mathrm{e}, 8}$ Schematics of the different phase morphologies achieved within pBTTT:PC ${ }_{61}$ BM:fatty acid additives are shown in Fig. $1 \mathrm{~b}$ (see for more details Ref. 3e) .

In a first set of experiments PDS spectra were measured for the different $\mathrm{pBTTT}: \mathrm{PC}_{61} \mathrm{BM}$ and $\mathrm{pBTTT}$ :additive: $\mathrm{PC}_{61} \mathrm{BM}$ systems of known degrees of intermixed phases. Absolute absorption coefficient spectra were obtained by matching the PDS spectra to absolute UV-Vis absorption spectra measured in the strongly absorbing region $(\mathrm{E}>1.9 \mathrm{eV})$ on samples with known film thickness. pBTTT has an absorption onset at $1.9 \mathrm{eV}$, while $\mathrm{PC}_{61} \mathrm{BM}$ has its onset at $1.7 \mathrm{eV}$ (Fig. 2a). The broad but weak absorption band at photon energies below $1.5 \mathrm{eV}$ originates from direct $\mathrm{CT}$ absorption. Tellingly, this absorption band varies in intensity when different additives are used to control the phase morphology of the $\mathrm{pBTTT}: \mathrm{PC}_{61} \mathrm{BM}$ blends. As-cast binaries without additives that consist solely of the co-crystal pBTTT:PC ${ }_{61} \mathrm{BM}(i)$ and, thus, feature the highest amount of molecular donor:acceptor interface that is possible to reach within this system, ${ }^{10}$ shows the most intense CT absorption band. The CT absorption band of pBTTT:Me7: $\mathrm{PC}_{61} \mathrm{BM}$ (ii), where still a large fraction of intimately mixed co-crystal phase

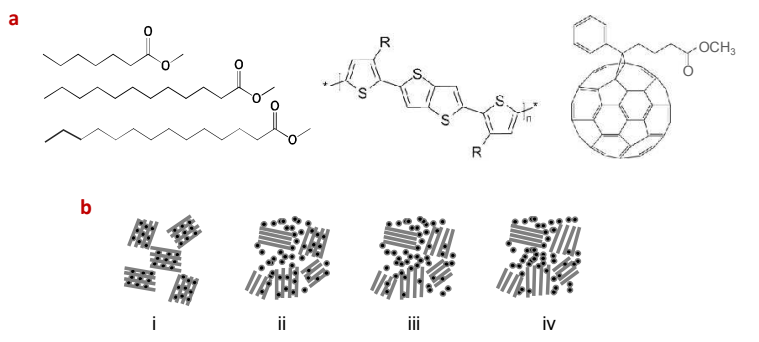

Figure 1. (a) From left to right: Chemical structures of the additives (Me7, Me12, Me14 from top to bottom), pBTTT, where R = $\left(\mathrm{CH}_{2}\right)_{15} \mathrm{CH}_{3}$ and $\mathrm{PC}_{61} \mathrm{BM}$. (b) Schematics that illustrate the different phase morphologies that can be obtained with these systems. From left to right: one-phase morphology ( $i$ ) realized when no additive is used; three phases can be obtained with Me7 (ii), and predominantly twophase systems are realized adding Me12 and Me14, respectively (iii and iv). ${ }^{3 \mathrm{e}}$

co-exists with relatively phase-pure polymer and fullerene domains, is reduced compared to the pBTTT:PC ${ }_{61} \mathrm{BM}$ binary. Most notably, the blends with Me12 (iii) and Me14 (iv) show a significant decrease in their CT absorption bands that we attribute to the strong phase separation between the polymer and the fullerene that is induced by the introduction of the additive in these blend systems. In agreement with these observations is the fact that the weak optical transition of $\mathrm{PC}_{61} \mathrm{BM}$ at $1.7 \mathrm{eV}$ (Fig. 2; data for neat $\mathrm{PC}_{61} \mathrm{BM}$ is shown for comparison: see dashed lines) is more pronounced for the system with Me14 (iv), supporting our structural picture that these systems comprise microscopically large fullerene domains and aggregates. Note also that after annealing these ternary films at $150{ }^{\circ} \mathrm{C}$, which will drive these multiphase systems towards the thermodynamically stable architecture composed mainly of the co-crystal phase ${ }^{3 \mathrm{e}}$ leads to the maximum number of molecular donor:acceptor interfaces as in the pBTTT:PC ${ }_{61} \mathrm{BM}$ binary. Indeed, a full recovery of the CT absorption signal is observed (Fig. 2b/Table $\mathrm{S} 1$ ). From the above it is evident that there is a direct correlation of amount of intermixed phases and the CT absorption. This finding is interesting when put in context with our previous studies where we have demonstrated that the highest charge formation is found in the three-phase morphology realized with Me7 (ii). We had assigned this to the large donor-acceptor interfaces within the co-crystal phase in these ternaries promoting charge generation while also providing a network of relatively phase-pure regions of the donor and the acceptor, which assist in maximizing long-lived carrier density and facilitate carrier extraction in the device. $3 \mathrm{e}$

Having established a structural correlation with the CT absorption of donor:fullerene blends we, thus, went on and exploited our model systems to determine the molar extinction coefficient, transition dipole moment and coupling matrix element of the pBTTT:PC ${ }_{61} \mathrm{BM}$ charge transfer complex. For this, we first calculated the molar density of pBTTT:fullerene contacts in such architectures to be $0.84 \mathrm{M}$ (see SI for details), using the structural details reported by McGehee and coworkers, who have recently determined the unit cell of the $\mathrm{pBTTT}: \mathrm{PC}_{71} \mathrm{BM}$ 

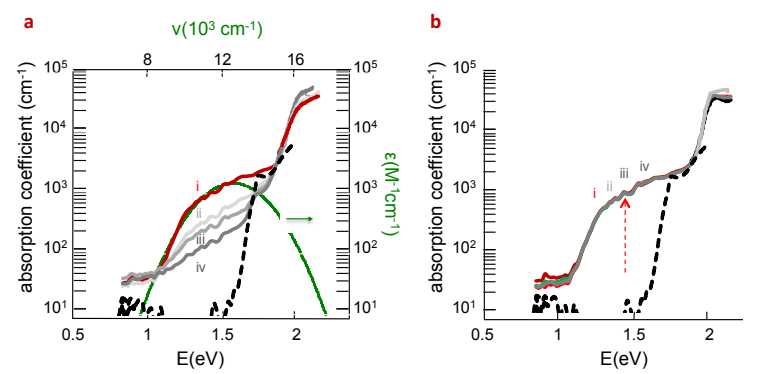

Figure 2. (a) PDS data obtained on $\mathrm{pBTTT}: \mathrm{PC}_{61} \mathrm{BM}$ samples of different content of intermixed phases: from the highly intermixed co-crystal phase (i) to multi-phase systems of decreasing amount of intermixed phase realized with addition of fatty acids. Data for neat $\mathrm{PC}_{61} \mathrm{BM}$ is shown for reference (dashed line). The graph also shows the molar absorption coefficient $\varepsilon$, as a function of wavenumber $v$ (or photon energy $E$ ) of a pBTTT:PC ${ }_{61} \mathrm{BM}$ charge transfer complex (green line);

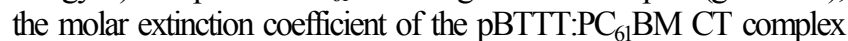
peaks at $\sim 1000 \mathrm{M}^{-1} \mathrm{~cm}^{-1}$, see Fig. S2 for more details. (b) PDS measured on the same films annealed at $150^{\circ} \mathrm{C}$ driving these two or three phasesystems to a single-phase structure comprised of the co-crystal phase.

co-crystal $^{11}$ that structurally is very similar to the pBTTT:PC ${ }_{61} \mathrm{BM}$ binary. ${ }^{10}$ Using the molar density and the absorption coefficient as well as the fact that the binaries comprising no additives (blend $i$ ) exclusively consist of the co-crystal phase, we can obtain a molar extinction coefficient for a single pBTTT:fullerene CT complex in the spectral region of CT absorption $(1 \mathrm{eV}<\mathrm{E}<1.6 \mathrm{eV})$. The result is shown in Fig. la (see also Fig. S2 in SI for further details). The molar extinction coefficient of the pBTTT:PC ${ }_{61} \mathrm{BM}$ CT complex peaks at $\sim 1000 \mathrm{M}$ ${ }^{1} \mathrm{~cm}^{-1}$, which is about 100 times lower than the peak molar extinction coefficient of the pBTTT chromophore $\left(10^{5} \mathrm{M}^{-1} \mathrm{~cm}^{-1}\right.$ at $2 \mathrm{eV}$ ) involved in the complex (with an equal amount of fullerene and pBTTT chromophores in a unit cell). In the next step, we determine important quantum mechanical parameters related to a single $\mathrm{pBTTT}: \mathrm{PC}_{61} \mathrm{BM}$ charge transfer complex. These parameters are becoming increasingly popular to determine properties of the donor:acceptor interface in organic solar cells. For example, the electronic coupling determines the rate of (back) electron transfer from the CT state to the ground state and the fraction of charge transferred in the ground state. Even though quantum chemical calculations of these parameters have been performed for model donor: $\mathrm{C}_{60}$ interfaces, ${ }^{12}$ an experimental determination of the transition dipole moment $M$ and the electronic coupling matrix element $V$ on a model polymer:fullerene system for OPV applications seems not to have been performed yet. We obtain values for $V$ and $M$ of, respectively, $27 \mathrm{meV}$ and $0.3 \mathrm{D}$ (see SI for details). The coupling $V$ of the CT state to the ground state is less than the coupling (or: transfer integral) between two pBTTT chains $(\sim 100-200$ $\mathrm{meV}) .{ }^{13}$ Hence, it is not surprising that CT states dissociate into free carriers when relatively phase-pure domains of either component are in the vicinity of this interface. Note in this context that a transition dipole moment of $0.3 \mathrm{D}$ is about one order of magnitude smaller compared to typical transition dipole moments of singlet transitions of organic molecules, but indeed visible in sensitive absorption measurements. ${ }^{14}$
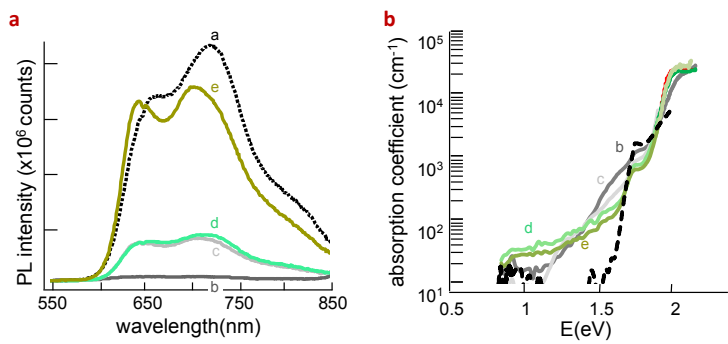

Figure 3. (Left) $\mathrm{PL}$ spectra of neat $\mathrm{P} 3 \mathrm{HT}(a), \mathrm{P} 3 \mathrm{HT}: \mathrm{PC}_{61} \mathrm{BM}(b)$ and blends of $\mathrm{P} 3 \mathrm{HT}$ :additive: $\mathrm{PC}_{61} \mathrm{BM}(c, d$ and $e)$. The emission of $\mathrm{P} 3 \mathrm{HT}$ is enhanced when Me7 (c) and Me14 (d) are introduced to the binary, using 0.5 molar equivalents of the respective additive to the monomer unit of the P3HT. The PL intensity further increases when higher amounts of Me14 were used (2.5 molar equivalents instead of 0.5), (e). (Right) PDS data obtained on $\mathrm{P} 3 \mathrm{HT}: \mathrm{PC}_{61} \mathrm{BM}$ (b) and P3HT:additives: $\mathrm{PC}_{61} \mathrm{BM}$ ternaries ( $c, d$ and $e$ ); data for $\mathrm{PC}_{61} \mathrm{BM}$ is shown for reference (dashed line).

We now turn to PDS as a means to compare the density of donor:acceptor contacts in our systems. Table S1 summaries the PDS data showing the percentages of co-crystal phase obtained in the binaries and ternaries studied here. It shows that the amount of molecular interfaces is reduced from close to $100 \%$ as present in the 1:1 pBTTT:PC ${ }_{61} \mathrm{BM}$ binary $(i)$, with $0.84 \mathrm{M}^{-1}$ of donor-acceptor contact, to only $\sim 15 \%$ in pBTTT:Me14:PC ${ }_{61} \mathrm{BM}$ ternaries which are composed of predominately phase-pure domains of pBTTT and $\mathrm{PC}_{61} \mathrm{BM}$, respectively $(i v)$. These values are in very good agreement with estimates we produced previously based on grazing-angle incidence wide-angle X-ray scattering (GIWAXS), Scanning Transmission X-ray microscopy (STXM) and PL decay measurements, ${ }^{3 \mathrm{e}}$ which had demonstrated the ability of asymmetrical additives to manipulate the co-crystal phase into structures comprised of two to three phases. The percentages obtained from STXM and PDS techniques should however be compared with caution. Both techniques cannot distinguish wether the fullerene is intercalated or not and, as compared to STXM, PDS will additionally probe polymer $/ \mathrm{PC}_{61} \mathrm{BM}$ cluster interfaces.

Since optical techniques such as PDS (or alternative sensitive EQE measurements when photovoltaic devices are available), can be used for a fast quantification of molecular donor:acceptor interfacial area without the need for synchrotron-irradiationbased techniques, we moved on and tested the generality of our strategy by applying it to the ubiquitous $\mathrm{P} 3 \mathrm{HT}: \mathrm{PC}_{61} \mathrm{BM}$ system. ${ }^{15}$ We varied the amount of molecular donor:acceptor interfaces using again methyl ester fatty acids as processing additives. Qualitatively, the effect of these additives on the intrachain order of P3HT could be followed analyzing the UV-Vis of the resulting binary and ternary systems. ${ }^{\text {b }}$ When using 1:1 (by weight) $\mathrm{P} 3 \mathrm{HT}: \mathrm{PC}_{61} \mathrm{BM}$ blends and adding between 0.5 and 2.5 molar equivalents of $\mathrm{Me} 7$ and $\mathrm{Me} 14$ per monomer unit of the P3HT, the 0-0 absorption transition of P3HT increases - indicative of an increase of P3HT aggregation (see Fig. S3 in SI); ${ }^{16}$ i.e., a higher fraction of phase-pure $\mathrm{P} 3 \mathrm{HT}$ domains is obtained where the polymer can aggregate better, leading to the observed higher $0-0$ absorption feature. This observation indicates that the 
polymer and fullerene may phase separate more strongly upon addition of these fatty acids, in agreement with the increase in PL intensity: a lower PL quenching is obtained for these blends compared to the additive-free $\mathrm{P} 3 \mathrm{HT}: \mathrm{PC}_{61} \mathrm{BM}$ binary, especially when high amounts of the long-chain additive Me14 were used (Fig. 3a). Finally, note that the most intense CT absorption band -visible as a broad shoulder at photon energies above $1.5 \mathrm{eV}$ (Fig. 3b) - is again observed for the system of the highest intermixing: i.e. the additive-free $\mathrm{P} 3 \mathrm{HT}: \mathrm{PC}_{61} \mathrm{BM}$ binary. In fact, similar to the $\mathrm{pBTTT}: \mathrm{PC}_{61} \mathrm{BM}$ systems, we find the CT absorption to decrease when the fullerene and the P3HT strongly phase separate, again induced with the addition of the fatty acids: we observe a reduction of almost $75 \%$ of the interfacial area when we introduce high amounts of Me14 into the P3HT:PC ${ }_{61} \mathrm{BM}$ blend, as Table S1 summarizes.

From the above it is, thus, evident that a direct correlation of the CT absorption band intensities and the presence of highly intermixed phases within polymer:fullerene blends exists. Using model systems, in which we manipulated the fraction of these intermixed regions with use of fatty acids, we demonstrated that PDS can be applied as a fast and reliable method to correlate the phase morphology of polymer:fullerene blend films with their optoelectronic features. This novel methodology can not only be used as a tool to obtain additional information on relevant $\mathrm{BHJ}$ systems, but also permit to provide experimentally determined parameters such as the electronic coupling between ground and CT states. The latter could so far only be calculated applying quantum chemical methods and it is indeed a crucial parameter in order to determine the electron transfer rates that are directly related to the device performance. Our work thus will allow future screening of other, relevant BHJ systems, including highperformance blends comprising high-performance donor polymers. It will also give insight in how to optimize these complex architectures with respect to the amount of intermixed phase that is needed to maximize charge generation without reaching a regime that is dominated by charge recombination.

\section{ASSOCIATED CONTENT}

Supporting Information.

Experimental details, additional figures and calculations as mentioned in the text. This material is available free of charge via the Internet at http://pubs.acs.org.

\section{AUTHOR INFORMATION}

\section{Corresponding Author}

*,†, Ester Buchaca-Domingo, E-mail: e.buchacadomingo@imperial.ac.uk; **, Koen Vandewal, E-mail: koen.vandewal@iapp.de

\section{Notes}

No competing financial interests have been declared.

\section{ACKNOWLEDGEMENT}

This work was supported by a Global Collaborative Research grant by KAUST (Award No.: CRG-1-2012-THO-015). EBD is in addition supported by a SABIC fellowship, NS by a ERC Starting Independent Research Fellowship under the grant agreement no. 279587 and JHB holds an Industrial Fellowship with the Royal Commission for the Exhibition of 1851. EBD is also grateful to the RSC for their support with a RSC International Author Journals Grant.

\section{REFERENCES}

1. Vandewal K., Himmelberger S. and Salleo A., Macromolecules, 2013,46, 6379. 2. (a) Tumbleston J. R., Stuart A. C., Gann E., You W. and Ade H., Adv. Funct. Mater., 2013, 23, 3463; (b) Collins B. A., Li Z., Tumbleston J. R., Gann E., McNeill C. R. and Ade H., Adv. Energy Mater., 2013, 3, 65; (c) Collins B. A., Li Z., McNeill C. R. and Ade H., Macromolecules, 2011, 44, 9747; (d) Treat N. D., Varotto A., Takacs C. J., Batara N., Al-Hashimi M., Heeney M. J., Heeger A. J., Wudl F., Hawker C. J. and Chabinyc M. L., J. Am. Chem. Soc., 2012, 134, 15869.

3. (a) Watts B., Belcher W. J., Thomsen L., Ade H. and Dastoor P. C., Macromolecules, 2009, 42, 8392; (b) Collins B. A., Gann E., Guignard L., He X., McNeill C. R. and Ade H., J. Phys. Chem. Lett., 2010, 1,3160; (c) Treat N. D., Brady M. A., Smith G., Toney M. F., Kramer E. J., Hawker C. J. and Chabinyc M. L., Adv. Energy Mater., 2011, 1, 1; (d) Pfannmöller M., Flügge H., Benner G., Wacker I., Sommer C., Hanselmann M., Schmale S., Schmidt H., Hamprecht F. A., Rabe T., Kowalsky W. and Schröder R. R., Nano Lett., 2011, 11, 3099; (e) Buchaca-Domingo E., Ferguson A. J., Jamieson F. C., McCarthy-Ward T., Shoaee S., Tumbleston J. R., Reid O. G., Yu L., Madec M. B., Pfannmöller M., Hermerschmidt F., Schröder R. R., Watkins S. E., Kopidakis N., Portale G., Amassian A., Heeney M., Ade H., Rumbles G., Durrant J. and Stingelin N., Mater. Horiz. 2014, 1, 270.

4. (a) McCulloch I., Heeney M., Bailey C., Genevicius K., MacDonald I., Shkunov M., Sparrowe D., Tiemey S., Wagner R., Zhang W., Chabinyc M. L., Kline R. J., McGehee M. D. and Toney M. F., Nat. Mater., 2006, 5, 328; (b) Rivnay J., Mannsfeld S. C. B., Miller C. E., Salleo A. and Toney M. F., Chem. Rev., 2012, 112,5488 .

5. (a) Chang J. F., Clark J., Zhao N., Sirringhaus H., Breiby D. W., Andreasen J. W., Nielsen M. M., Giles M., Heeney M. and McCulloch I., Phys. Rev. B: Condens. Matter Mater. Phys., 2006, 74, 115318; (b) Zhang R., Li B., Iovu M. C., Jeffries-El M., Sauvé G., Cooper J., Jia S., Tristram-Nagle S., Smilgies D. M., Lambeth D. N., McCullough R. D. and Kowalewski T., J. Am. Chem. Soc., 2006, 128, 3480.

6. (a) Cates N. C., Gysel R., Beiley Z., Miller C. E., Toney M. F., Heeney M., McCulloch I. and McGehee M. D, Nano Lett., 2009, 9, 4153; (b) Miller N. C., Cho E., Gysel R., Risko C., Coropceanu V., Miller C. E., Sweetnam S., Sellinger A., Heeney M., McCulloch I., Brédas J. L., Toney M. F. and McGehee M. D., $A d v$. Energy Mater., 2012, 2, 1208.

7. (a) He X., Collins B. A., Watts B., Ade H. and McNeill C. R., Small, 2012, 8, 1920; (b) Hitchoock A. P., Tyliszezak T., Koprinarov I., Stover H., Li W. H., Heng T. M., Murti K., Gerroir P., Dutcher J. R., Dalnoki-Veress K. and Ade H. W., AIP Conf. Proc., 2000, 507, 231.

8. Scarongella M., De Jonghe-Risse J., Buchaca-Domingo E., Causa M., Fei Z., Heeney M., Stingelin N. and Banerji N., J. Am. Chem. Soc., 2015, 137, 2908.

9 (a) Gu Y., Wang C. and Russell, Adv. Energy Matter., 2012, 2, 683; (b) Shin N., Richter L. J., Herzing A. A., Kline R. J. and DeLongchamp D. M., Adv. Energy Mater., 2013,3,938.

10. (a) Jamieson F. C., Buchaca-Domingo E., McCarthy-Ward T., Heeney M., Stingelin N. and Durrant J. R., Chem. Sci., 2012, 3, 485; (b) Rance W. L., Ferguson A. J., McCarthy-Ward T., Heeney M., Ginley D. S., Olson D. C., Rumbles G. and Kopidakis N., ACS Nano, 2011, 5, 5635;

11. Miller N. C., Cho E., Junk M. J. N., Gysel R., Risko C., Kim D., Sweetnam S., Miller C. E., Richter L. J., Kline R. J., Heeney M., McCulloch I., Amassian A., Acevedo-Feliz D., Knox C. , Hansen M. R., Dudenko D., Chmelka B. F., Toney M. F., Brédas J. L. and McGehee M. D., Adv, Mater., 2012, 24, 6071.

12. (a) Yi Y., Coropceanu V. and Bredas J. L., J. Mater. Chem. 2011, 21, 1479; (b) Liu T. and Troisi A., J. Phys. Chem. C, 2011, 115, 2406.

13. (a) Rivnay J., Noriega R., Northrup J. E., Kline R. J., Toney M. F. and Salleo A., Physical Review B , 2011, 83, 121306.

14. Turro N. J., Ramamurthy V. and Scaiano J. C., Principles of molecular photochemistry: an introduction, 2009, University science books, Sausalito, California, USA.

15. Goris L., Poruba A., Hod'ákova L., Vaněček M. , Haenen K., Nesládek M. , Wagner P., Vanderzande D. , De Schepper L. and Manca J. V., Appl. Phys. Lett., $2006,88,052113$.

16. (a) Clark J., Silva C., Friend R. H. and Spanno F. C., Phys. Review Lett., 2007, 98, 206406; (b) Reid O. G., Nekuda-Malik J. A., Latini G., Dayal S., Kopidakis N., Silva C., Stingelin N. and Rumbles G., J. Polym. Sci., part B: Polym. Phys., 2012, 50,27 . 


\section{Page 5 of 5}

Journal of the American Chemical Society

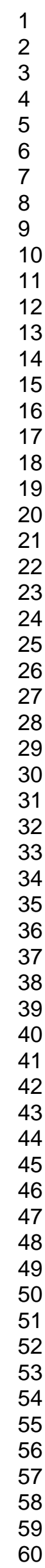

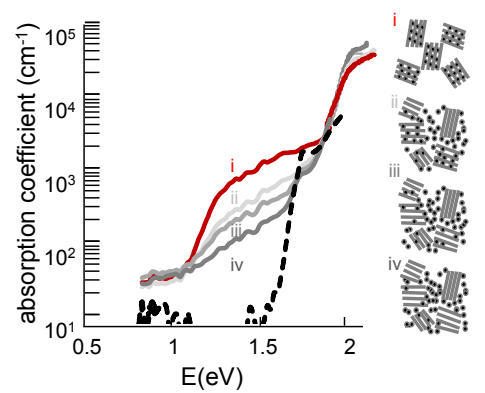

13

14

16

17

18

19

20

23

24

25

26

27

29

30

31

33

34

35

36

37

38

39

40

41

42

44

45

46

47

48

49

51

52

53

54

55

57

58

59

60 